\title{
Current and Thermal Variations to Westerly Wind Bursts in the Equatorial Pacific Ocean
}

\author{
Yiing Jang Yang ${ }^{1, *}$, Tswen Yung Tang ${ }^{2}$, and Robert H. Weisberg ${ }^{3}$
}

(Manuscript received 23 January 2003, in final form 5 March 2004)

\begin{abstract}
The observed upper ocean zonal current, $20^{\circ} \mathrm{C}$ isotherm depth, and zonal wind stress, calculated from the European Centre for Medium Range Weather Forecasts (ECMWF) model output, were examined in the equatorial Pacific during the period of frequent Westerly Wind Bursts (WWBs) in the period October-April from 1988 (La Niña year) to 1992 (EI Niño year). WWBs increased in strength and number, shifting eastwardly towards El Niño, and causing the frequent reversal of surface current, and its vertical gradient within the western basin. Similar features were also observed in the west-central basin, but only during the EI Niño event. The reversal of surface zonal current in the central and eastern basins was generally accompanied by surfacing of the Equatorial Undercurrent (EUC), though the vertical gradient of zonal current velocity in the upper ocean never reversed. Fluctuations in upper ocean zonal currents in response to the WWBs were largest in the western basin, while fluctuations in $20^{\circ} \mathrm{C}$ isotherm depths were largest in the central and eastern basins. Discernible peaks in ocean responses due to WWBs were modulated in their propagation away from the forced region.

Since WWBs occurred in succession at various locations, ocean responses to each individual WWB were interfered with by other WWB events. A simple analytical model was therefore devised to describe the temporal and spatial evolution of the interference patterns in relation to various locations and WWB events. Pattern evolutions for both upper ocean zonal current and thermal structures were further modulated by easterly wind fluctuations east of the dateline. Tracing individual wave modes using peakto-peak comparisons is therefore a subjective process.
\end{abstract}

\footnotetext{
${ }^{1}$ Department of Marine Science, Chinese Naval Academy, Kaohsiung, Taiwan, ROC

${ }^{2}$ Institute of Oceanography, National Taiwan University, Taipei, Taiwan, ROC

${ }^{3}$ College of Marine Science, University of South Florida, St. Petersburg, Florida, USA

* Corresponding author address.Dr. Yiing Jang Yang, Department of Marine Science, Chinese Naval Academy, P. O. Box 90175, Tsoying, Kaohsiung, Taiwan, ROC; E-mail: yjyang@cna.edu.tw
} 


\section{(Key words: El Niño, La Niña, Westerly Wind Burst, South Equatorial Current, Equatorial Undercurrent, Kelvin wave, Rossby wave)}

\section{INTRODUCTION}

Generally associated with tropical cyclone formation, Westerly Wind Bursts (WWBs) can frequently be found in the western tropical Pacific Ocean, particularly between the months of November and March (Keen 1982). Some WWBs last just a few days and contain speeds of 4-5 $\mathrm{m} \mathrm{s}^{-1}$ (Keen 1988), while others are more energetic and can last anywhere from 1-3 weeks (Keen 1982; 1988). Giese and Harrison (1991) have cataloged WWB episodes into four types, $\mathrm{N}, \mathrm{C}, \mathrm{S}$, and FS, according to the position of maximum westerly winds with respect to the equator (north of, centered on, south of, or far south near the dateline). The C-type WWB generates the largest equatorially trapped Kelvin wave, and therefore induces the largest equatorial ocean responses. During the onset of the El Niño phase of the El Niño-Southern Oscillation (ENSO), WWBs were found to increase in both magnitude and frequency (e.g., Luther et al. (1983); McPhaden et al. (1988); Harrison and Giese (1991); McPhaden and Hayes (1991); McPhaden et al. 1992), tending to shift eastward and in the direction of the equator (Kindle and Phoebus 1995). Easterly winds over the central equatorial Pacific tend to simultaneously weaken (e.g., Wyrtki 1975; Wyrtki and Meyers 1976), suggesting (Keen 1982) that the onset of ENSO could be initiated by WWBs. Tang and Weisberg (1984) have adopted a simple analytical model to describe the temporal and spatial evolution of ocean responses to the 19821983 El Niño event through an eastward translation of a westerly wind anomaly initially formed west of the dateline (Rasmusson et al. 1983). This westerly wind anomaly was found to be closely related to the WWBs (Harrison and Giese 1991).

Ocean responses to WWBs have been well documented. A reversal of surface zonal currents along $170^{\circ} \mathrm{E}$ between $4^{\circ} \mathrm{S}$ and $4^{\circ} \mathrm{N}$ was observed by Hisard et al. (1970) following the 1967 intensification of westerly winds. Analyzing moored current meter data along with Shipboard Acoustic Doppler Current Profiler (Sb-ADCP) data at $0^{\circ} \mathrm{N}$ and $165^{\circ} \mathrm{E}$ in the winter of 1989, McPhaden et al. (1992) discovered an eastward surface jet of 400-600 km width, 100$150 \mathrm{~m}$ depth, and maximum speed exceeding $100 \mathrm{~cm} \mathrm{~s}^{-1}$ centered on the equator between $135^{\circ} \mathrm{E}$ and the dateline.

During the onset of the 1982-1983 El Niño and under the influence of strong WWBs, Firing et al. (1983) found an eastward surface zonal current and a reduced Equatorial Undercurrent (EUC) at $0^{\circ} \mathrm{N}$ and $159^{\circ} \mathrm{W}$. McPhaden et al. (1988) also described the response of the equatorial Pacific Ocean to a WWB preceding the 1986-1987 El Niño. Variability of sea level, dynamic height, and zonal transport east of the dateline was attributed to a Kelvin wave with an apparent phase speed of $302 \mathrm{~cm} \mathrm{~s}^{-1}$. Local ocean responses to WWBs west of the dateline $\left(0^{\circ} \mathrm{N}, 165^{\circ} \mathrm{E}\right)$ included a deepened thermocline, reductions in sea surface temperature (SST) and near-surface stratification, reversals of surface zonal current and upper ocean vertical shear, and deceleration of the EUC. McPhaden (1993) noted similar features of ocean responses to WWBs during the 1991-1992 El Niño event. Using a reduced-gravity, multi-layer, numerical model forced by wind stress from the U.S. Navy's Atmospheric Global Operational 
Analysis/Forecast System, Kindle and Phoebus (1995) also studied ocean response during the 1991-1992 sequence of events, discerning 10 distinct WWB episodes, each with their own spatial and temporal distributions. The three most prominent episodes occurred between November 1991 and January 1992. The importance of both the first and second vertical mode Kelvin waves was determined upon comparison of model results with sea level data in the eastern basin. Kessler and McPhaden (1995a; 1995b) and Kessler et al. (1995) discovered a correlation between this series of WWBs and several strong Madden-Julian Oscillations (MJOs), or planetary-scale, eastward-propagating intraseasonal convection fluctuations in the tropical atmosphere between the Indian and Pacific Oceans. These MJO events were generated by a series of downwelling equatorial Kelvin waves propagating east from the dateline at about $240 \mathrm{~cm} \mathrm{~s}^{-1}$. Wijesekera and Gregg (1996) studied surface layer response to WWBs in the warm pool of the equatorial Pacific between November and December of 1992 (prior to the 1993 El Niño), concluding the dominance of the advective term in the heat budget. Symth et al. $(1996 a, b)$ found that WWB variations on near-inertial timescales interfered with wave response, exerting considerable influence on observed currents.

The present study further examines WWB variability between the 1988 La Niña and the 1992 El Niño as well as the corresponding zonal current and thermal response in the equatorial Pacific. The evolution of zonal current and $20^{\circ} \mathrm{C}$ isotherm depth responses to a series of WWBs occurring at the onset of the 1991-1992 El Niño event is described in relation to their interference patterns. The paper is organized as follows: Section 2 examines basin-wide zonal wind stress, $20^{\circ} \mathrm{C}$ isotherm depth, and zonal current velocity fluctuations in the upper ocean from 1988-1992 during the period between October and April when WWBs are most common. Water temperature and current velocity were obtained from the Tropical Atmosphere Ocean (TAO) array deployed in 1985 (Hayes et al. 1991). Wind data from the European Centre for Medium Range Weather Forecasts (ECMWF) model was used to demonstrate the temporal and spatial variability of WWBs. Attention was focused upon the initiation of the 1991-1992 El Niño, when WWBs were strongest. Section 3 focuses on the evolution of basin-wide ocean responses via an analytical ocean model based on a series of WWBs occurring between October 1991 and April 1992. Interference to ocean responses by various WWBs was found to be significant, with the resultant ocean response model compared to observations of the vertically-averaged upper ocean zonal velocity component and $20^{\circ} \mathrm{C}$ isotherm depth. Section 4 offers a discussion and summary of results.

\section{DATA}

Figure 1 shows the Pacific Ocean basin-wide ECMWF surface zonal wind stress $\left(\tau^{x}\right)$ on the equator from October to April in 1988, 1989, 1990 and 1991. The $\tau^{x}$ was computed by

$$
\tau^{x}=\rho_{a} C_{10} W w_{x}, W=\sqrt{w_{x}^{2}+w_{y}^{2}},
$$


where the $\rho_{a}$ is air density, $w_{x}$ and $w_{y}$ are the zonal and meridional wind velocity components, respectively, and $C_{10}$ is the drag coefficient at 10-m height following Trenberth et al. 1989 such that

$$
\begin{aligned}
& C_{10}=(0.49+0.065 W) \times 10^{-3} \text { for } W>10 \mathrm{~m} \mathrm{~s}^{-1}, \\
& C_{10}=1.14 \times 10^{-3} \text { for } 3 \leq W \leq 10 \mathrm{~m} \mathrm{~s}^{-1}, \\
& C_{10}=\left(0.62+\frac{1.56}{W}\right) \times 10^{-3} \text { for } W<3 \mathrm{~m} \mathrm{~s}^{-1} .
\end{aligned}
$$

The $\tau^{x}$ zonal resolution is $2.5^{\circ}$, the time interval is 12 hours, and the detailed analysis appeared in Yang et al. 1997. The WWBs, highlighted occurred in November and December 1989, January, February, March, November and December 1990, March, November and December 1991, and January 1992, etc. It is defined such that the westerly wind has fetch larger than $10^{\circ}$, duration longer than 3 days and stress larger than 0.35 dyne $\mathrm{cm}^{-2}$. Following the 1988 La Niña, the WWBs gradually increased in amplitude, fetch and frequency, reaching their maximum strength and eastward movement during the 1991-1992 El Niño in the western equatorial Pacific. Only at the peak of the El Niño warming were WWBs found east of the dateline. With the progressive intensification of WWBs from year to year, easterly winds gradually reduced and shifted east of the dateline. Three distinct WWB events were observed from 1991-1992, preceding the collapse of easterly winds in early March (Kindle and Phoebus 1995). Located immediately west of the dateline, the first event occurred around November 1991 with a maximum westerly wind stress of over 1.5 dyne $\mathrm{cm}^{-2}$, a duration of around 15 days, and a fetch of $4000 \mathrm{~km}$. This wind patch follows a simple temporal and spatial distribution and appears to be stationary. Observed between late December of 1991 and early January of 1992, the second WWB exhibited more complex temporal and spatial variations than the first, and contained a series of tropical cyclones that were also confined west of the dateline. Dissimilar from the previous two events, the third WWB occurring in late January of 1992 was centered east of the dateline around $160^{\circ} \mathrm{W}$, and exhibited a fetch and amplitude smaller than the first two. With more complicated temporal and spatial variations than the first one, this event contained at least two tropical cyclones.

In addition to these three main WWB events, several smaller events with short durations, small fetches and amplitudes were also observed. Although easterly wind stress generally remained stable during the WWB episodes, it still exhibited some significant fluctuations in the central basin. It is important to note that relatively large WWB events were also observed during the non-El Niño years, though their frequency was less and their location further west.

Variations in the ocean's zonal current velocity in the upper $200 \mathrm{~m}$ from January 1988 to July 1992 are indicated as five-day means on the equator at $165^{\circ} \mathrm{E}, 170^{\circ} \mathrm{W}, 140^{\circ} \mathrm{W}$ and $110^{\circ} \mathrm{W}$ (see Fig. 2). Zonal current velocity at $165^{\circ} \mathrm{E}, 140^{\circ} \mathrm{W}$ and $110^{\circ} \mathrm{W}$ are taken from the TAO Project Office at the Pacific Marine Environmental Laboratory/National Oceanic Atmospheric 

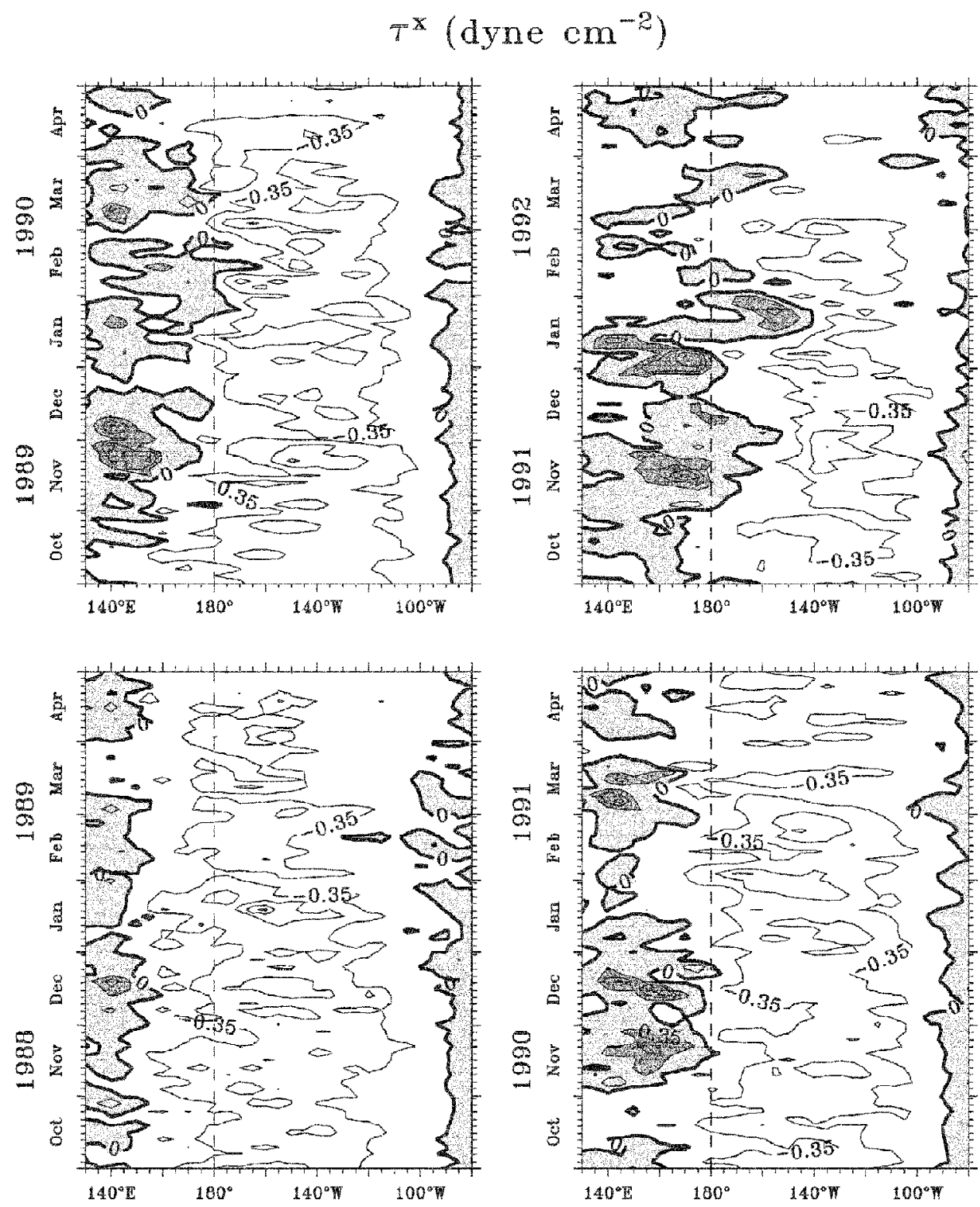

Fig. 1. Daily mean zonal wind stress distribution as a function of time and longitude. The four panels indicate zonal wind stress variations from October to April in 1988, 1989, 1990 and 1991, respectively. Longitude ranges from $130^{\circ} \mathrm{E}$ to $80^{\circ} \mathrm{W}$; contour interval is 0.35 dyne $\mathrm{cm}^{-2}$. Clear (shaded) regions indicate easterly (westerly) wind stress, dark shaded regions indicate the WWBs, bold lines signify the absence of wind stress, and the dashed line indicates the dateline. 


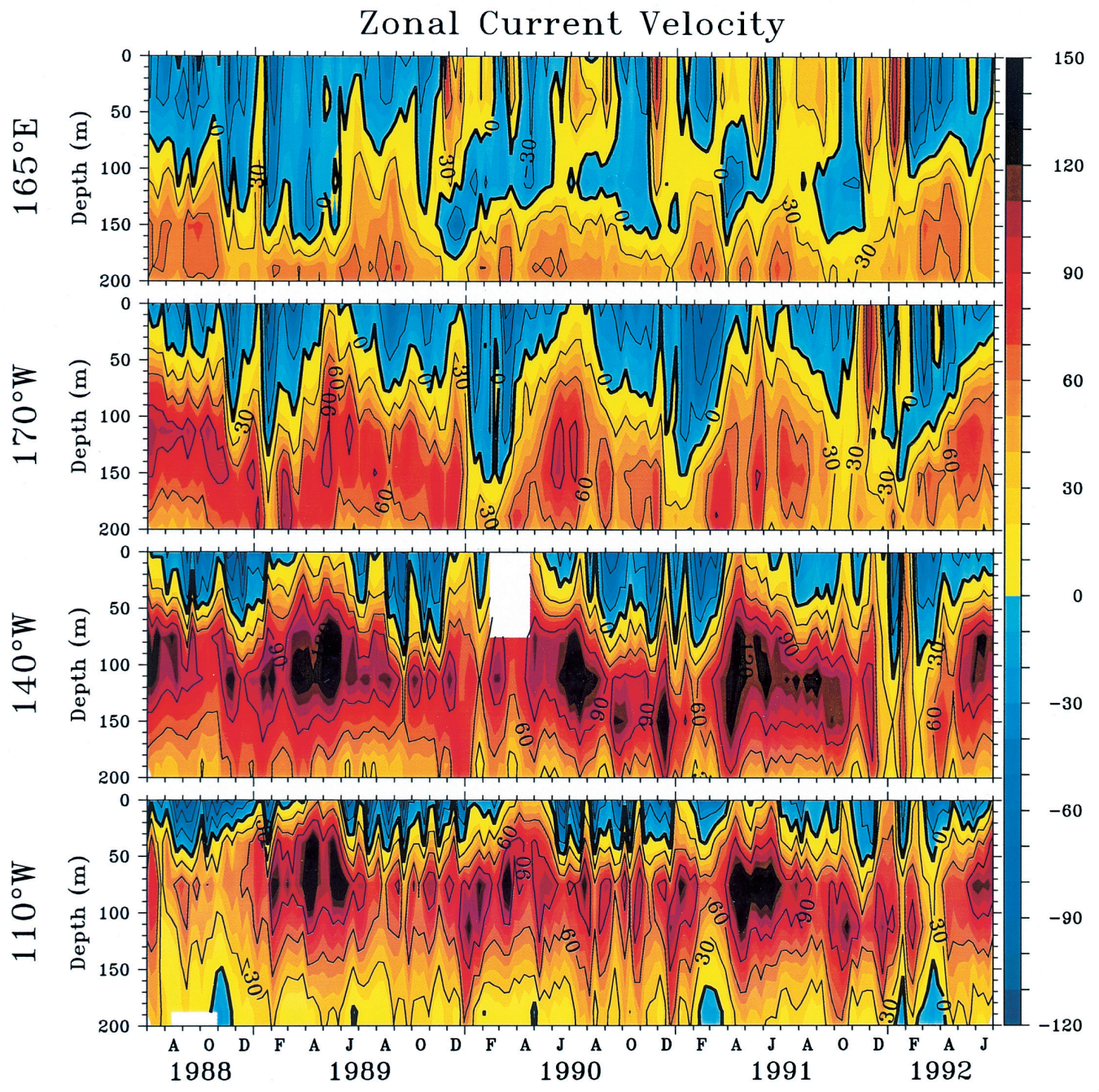

Fig. 2. Five-day mean zonal current velocity in upper $200 \mathrm{~m}$ at $165^{\circ} \mathrm{E}, 170^{\circ} \mathrm{W}$, $140^{\circ} \mathrm{W}$ and $110^{\circ} \mathrm{W}$ on the equator from July 1988 to June 1992 . The positive and negative values represent the eastward and westward current, respectively. Contour interval is $30 \mathrm{~cm} \mathrm{~s}^{-1}$ and the bold line indicates a zonal current velocity of zero. The current data is provided by the TAO Project Office, Pacific Marine Environmental Laboratory, National Oceanic and Atmospheric Administration, USA, except $170^{\circ} \mathrm{W}$. 
Administration (PMEL/NOAA) (McPhaden et al. 1992). Zonal current velocity at $170^{\circ} \mathrm{W}$ is taken from the University of South Florida's (USF) subsurface Acoustic Doppler Current Profiler (ADCP) mooring (Weisberg and Hayes 1995). The sites at $165^{\circ} \mathrm{E}, 170^{\circ} \mathrm{W}, 140^{\circ} \mathrm{W}$ and $110^{\circ} \mathrm{W}$ are hereafter referred to as the western, west-central, central, and eastern equatorial Pacific, respectively.

The westward South Equatorial Current (SEC) can generally be found in the surface layer, whilst the eastward EUC generally occurs beneath the SEC. The depth of the SEC and the EUC core generally reduces from west to east, while their largest amplitudes can be found in the west-central and eastern basin, respectively. Western basin surface current frequently reverses, with the frequency and velocity of its eastward surface flow increasing towards the peak El Niño year. The surface current in the west-central basin has also been known to reverse, but not as often nor for as long as the western basin. The western and west-central basins can also be distinguished by the nature of SEC reversal: reversals of eastward surface flow in the west generally have a surface maximum, while the vertical gradient of upper ocean zonal velocity reverses; and though surfacing of the EUC is observed at stations farther east, the vertical gradient of upper ocean zonal current shows no signs of reversal (Kessler and McPhaden 1995a; Weisberg and Hayes 1995; Qiao and Weisberg 1997).

In order to thoroughly examine the zonal current velocity fluctuations during the period between October and April (1988-1992), equatorial daily mean zonal current velocities at $165^{\circ} \mathrm{E}, 170^{\circ} \mathrm{W}, 140^{\circ} \mathrm{W}$ and $110^{\circ} \mathrm{W}$ are shown in Figs. $3,4,5$ and 6 , respectively. In the western basin, each SEC reversal, which occurred in November and December 1989, January, February, March, November and December 1990, March, November and December 1991, and January 1992 (Fig. 3), can be related to a corresponding WWB (Fig. 1), though eastward speed is not always proportional to the strength of westerly wind stress, and time lags between WWB and surface current reversal are not always the same. In addition, surface current reversal is not necessarily accompanied by the reversal of the surface zonal velocity vertical gradient. In the year of El Niño, there were two distinct surface current reversal events that seem to correspond to the first two WWB events described above. The second event in January 1992 has larger amplitude but shorter duration than the one in November 1991. No correspondence, however, was found between surface current reversal and the third WWB event occurring east of the dateline towards the end of January 1992. Theoretically, an upwelling Rossby wave with eastward current should have been seen at this location.

Drawing similar comparisons between WWB events and zonal current fluctuations at $170^{\circ} \mathrm{W}$ (Fig. 4) is more difficult, particularly during non-El Niño years. The appearance of eastward flow at the surface is generally, but not necessarily, due to EUC surfacing. Similar to $165^{\circ} \mathrm{E}$, two distinct events were evident when the surface current and its vertical gradient both reversed sign during the initial period of the 1991-1992 El Niño. The first (November 1991) has a larger amplitude and longer duration than the second (January 1992), while the second eastward jet contains a double peak, one of which could have been induced by a third WWB event occurring in late January when $170^{\circ} \mathrm{W}$ was within range of its extended fetch. Yet since time lags between $165^{\circ} \mathrm{E}$ and $170^{\circ} \mathrm{W}$ for the first and second surface eastward jets differ, simply tracing the propagation of an equatorial wave mode via peak-to-peak comparisons cannot yield an adequate description of zonal current fluctuations. 
Zonal Current Velocity at $0^{\circ} \mathrm{N}, 165^{\circ} \mathrm{E}$
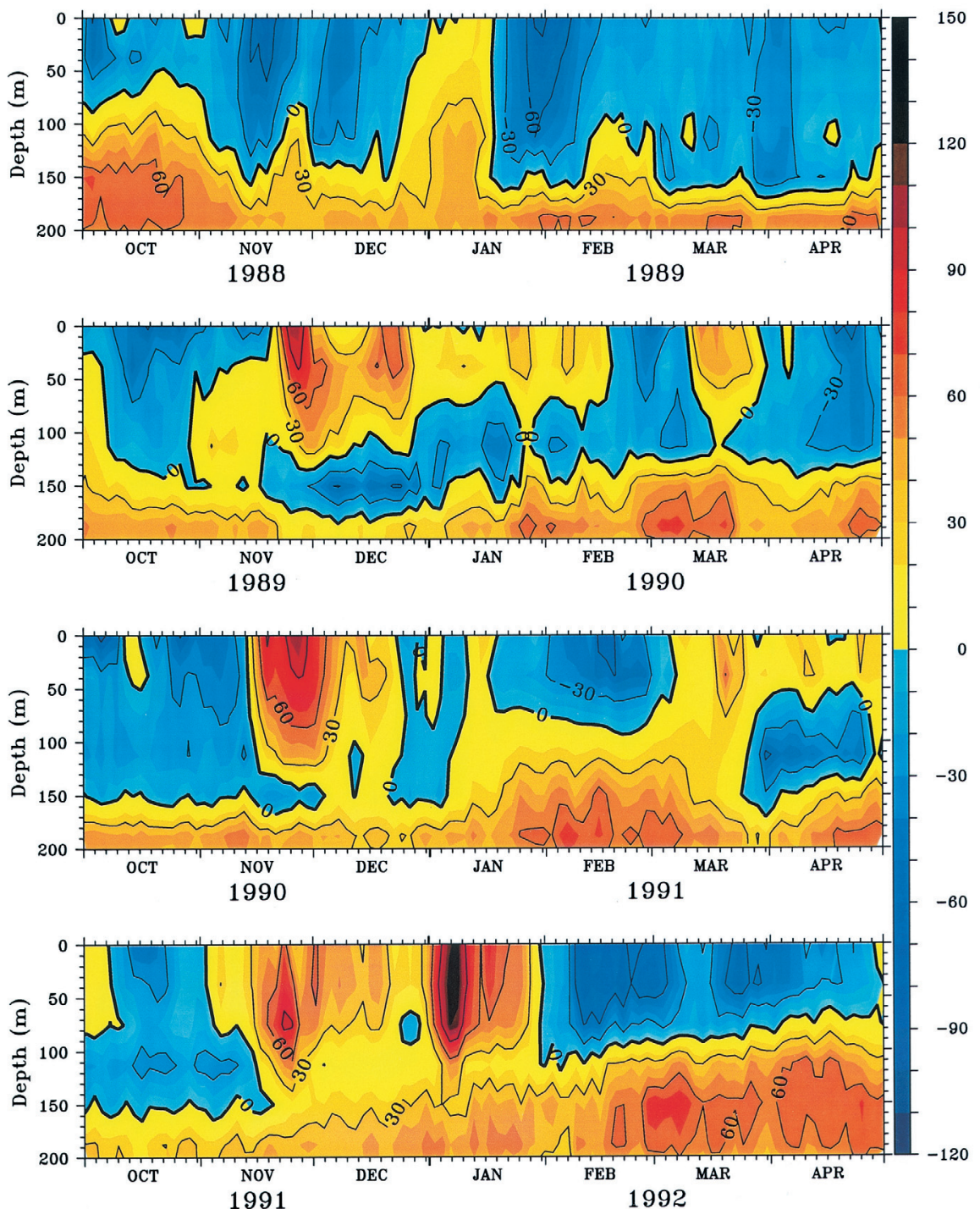

Fig. 3. Daily mean of zonal current velocity as a function of time and depth at $0^{\circ} \mathrm{N}, 165^{\circ} \mathrm{E}$. The time series from top to bottom runs from October to April 1988, 1989, 1990 and 1991. The positive and negative values represent the eastward and westward current, respectively. Depth ranges from $0 \mathrm{~m}$ to $200 \mathrm{~m}$, contour interval is $30 \mathrm{~cm} \mathrm{~s}^{-1}$, and the bold line is zero velocity. The current data is provided by the TAO Project Office, Pacific Marine Environmental Laboratory, National Oceanic and Atmospheric Administration, USA. 
Zonal Current Velocity at $0^{\circ} \mathrm{N}, 170^{\circ} \mathrm{W}$
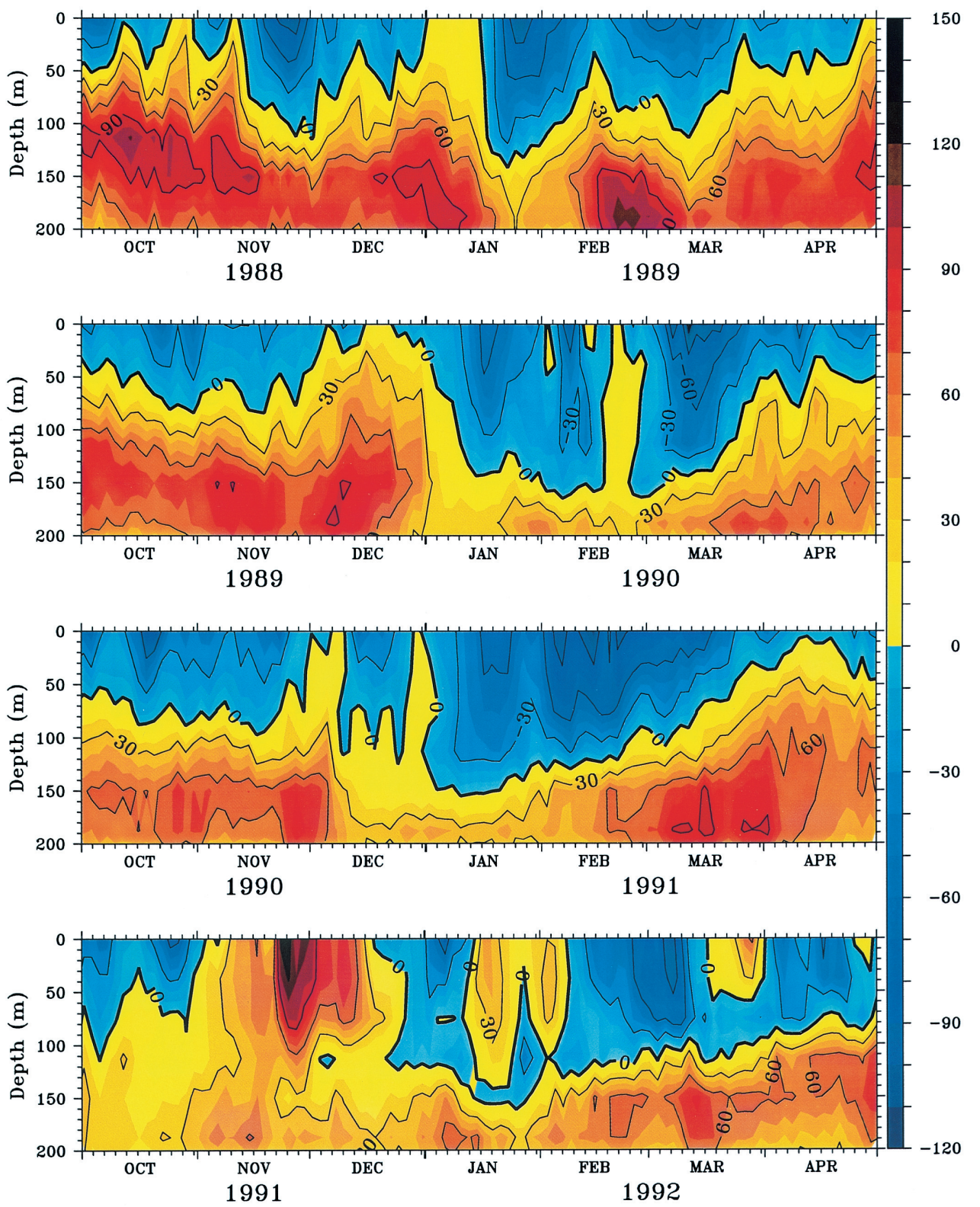

Fig. 4. Same as Fig. 3 except at $0^{\circ} \mathrm{N}, 170^{\circ} \mathrm{W}$. 
It is increasingly more difficult to trace WWB-induced surface current reversals into the central and eastern basins (Figs. 5, 6). Considering that upper ocean response is expected to propagate as a Kelvin wave, the two eastward jets induced by the western basin WWBs can barely be followed into the central and eastern basins, even during the 1991-1992 El Niño year. Visually tracing ocean response to individual WWBs is therefore a subjective process.

In order to further assess the temporal and spatial pattern evolution of SEC reversal along the equator, zonal current velocity was vertically averaged over the upper $100 \mathrm{~m}$. Results for $156^{\circ} \mathrm{E}, 165^{\circ} \mathrm{E}, 170^{\circ} \mathrm{W}, 140^{\circ} \mathrm{W}$ and $110^{\circ} \mathrm{W}$ from October 1991 to April 1992 can be found in Fig. 7 with periods of the three most distinct WWB events highlighted. The additional time series at $156^{\circ} \mathrm{E}$ was measured using a downward-looking ADCP deployed by PMEL/NOAA in the beginning of July 1991 (Sprintall and McPhaden 1994). Though modulations of easterly propagating jets are observed at each location, individual time evolutions vary. The first eastward jet induced by the first WWB event, for instance, is clearly observable at $165^{\circ} \mathrm{E}$ and $170^{\circ} \mathrm{W}$. Since the wind patch was confined to the west of the dateline, a free Kelvin wave propagating eastward without significant change in shape should theoretically be seen east of the dateline, but data indicates a gradual deterioration of the eastward jet to the point where it becomes difficult to recognize at $110^{\circ} \mathrm{W}$. Apparent phase speeds estimated from peak-to-peak comparison between $170^{\circ} \mathrm{W}$ and $140^{\circ} \mathrm{W}$ are also different from those between $140^{\circ} \mathrm{W}$ and $110^{\circ} \mathrm{W}$, suggesting modulation of the jets during their eastward propagation. This is even more apparent for the second eastward jet, which contains double peaks at $170^{\circ} \mathrm{W}$ but only one peak at $140^{\circ} \mathrm{W}$ and $110^{\circ} \mathrm{W}$.

Figure 8 provides a similar representation of daily mean $20^{\circ} \mathrm{C}$ isotherm depths. The $20^{\circ} \mathrm{C}$ isotherm depth was computed by linear interpolated from temperature measurements of $\mathrm{Au}$ tonomous Temperature Line Acquisition System (ATLAS) buoys of PMEL/NOAA (Hayes et al. 1991; McPhaden 1993). The expendable bathythermograph (XBT) and ATLAS buoy measurements indicated the $20^{\circ} \mathrm{C}$ isotherm depth is around the middle of thermoclinic (Kessler et al., 1990, 1996). Even in the case of relatively strong WWBs, $20^{\circ} \mathrm{C}$ isotherm depth fluctuations in the western basin were minor. Isotherm depth fluctuations east of $170^{\circ} \mathrm{W}$, however, were relatively large. Two large peaks in isotherm depth variation were found at $170^{\circ} \mathrm{W}, 140^{\circ} \mathrm{W}$ and $110^{\circ} \mathrm{W}$ in the period between November and February. In contrast to zonal velocity data, peak-to-peak comparisons between longitudes for $20^{\circ} \mathrm{C}$ isotherm depth show eastward propagation at velocities of approximately $250 \mathrm{~cm} \mathrm{~s}^{-1}$, indicative of a first vertical mode Kelvin wave.

The foregoing descriptions indicate that WWBs induce ocean responses both spatially and temporally modulated by the forcing function as well as interference between different forcing events. In attempt to render a dynamic analysis of these features, a simple long equatorial wave model concentrating on the period between October 1991 and April 1992 is applied in the next section. 
Zonal Current Velocity at $0^{\circ} \mathrm{N}, 140^{\circ} \mathrm{W}$
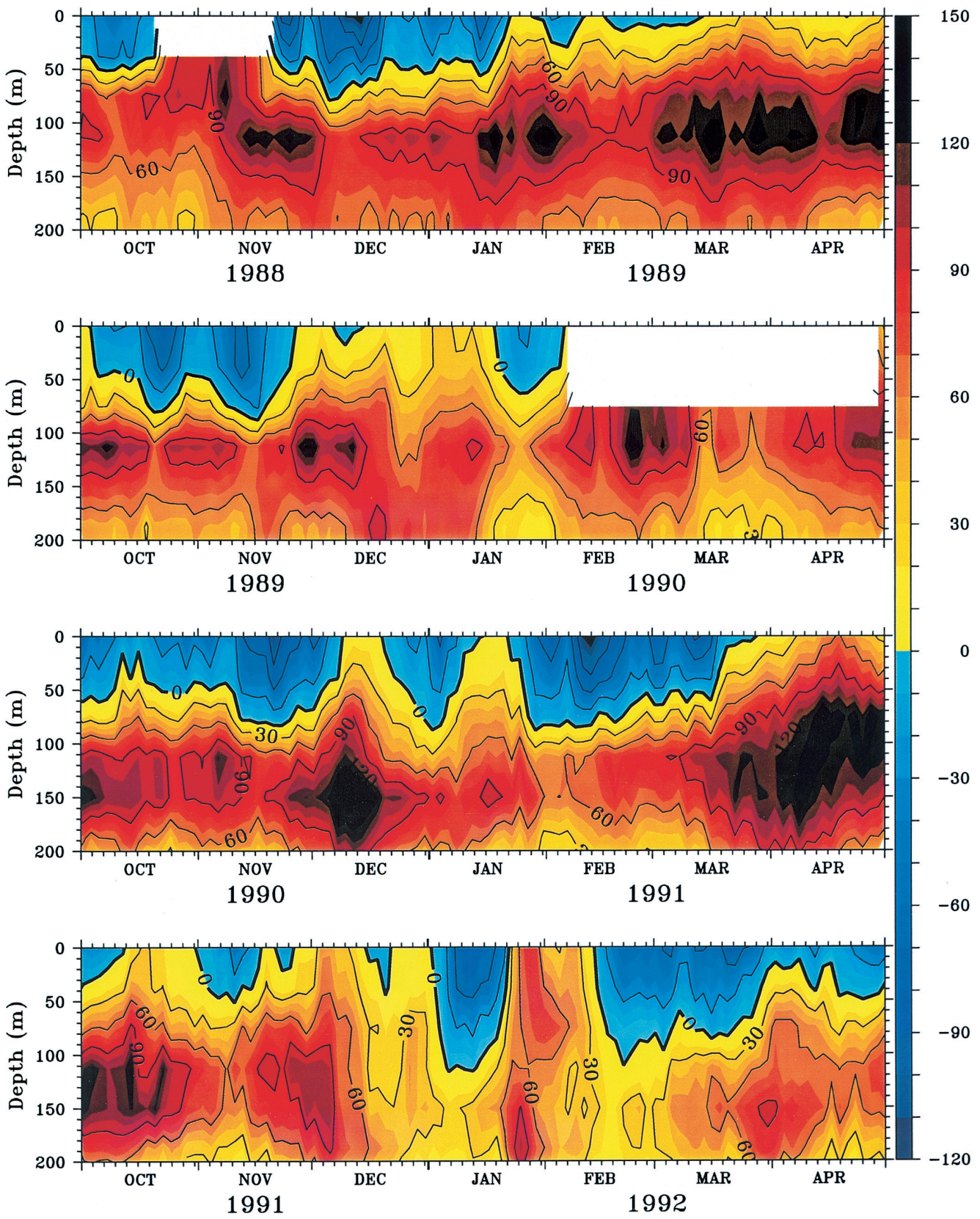

Fig. 5. Same as Fig. 3 except at $0^{\circ} \mathrm{N}, 140^{\circ} \mathrm{W}$. 


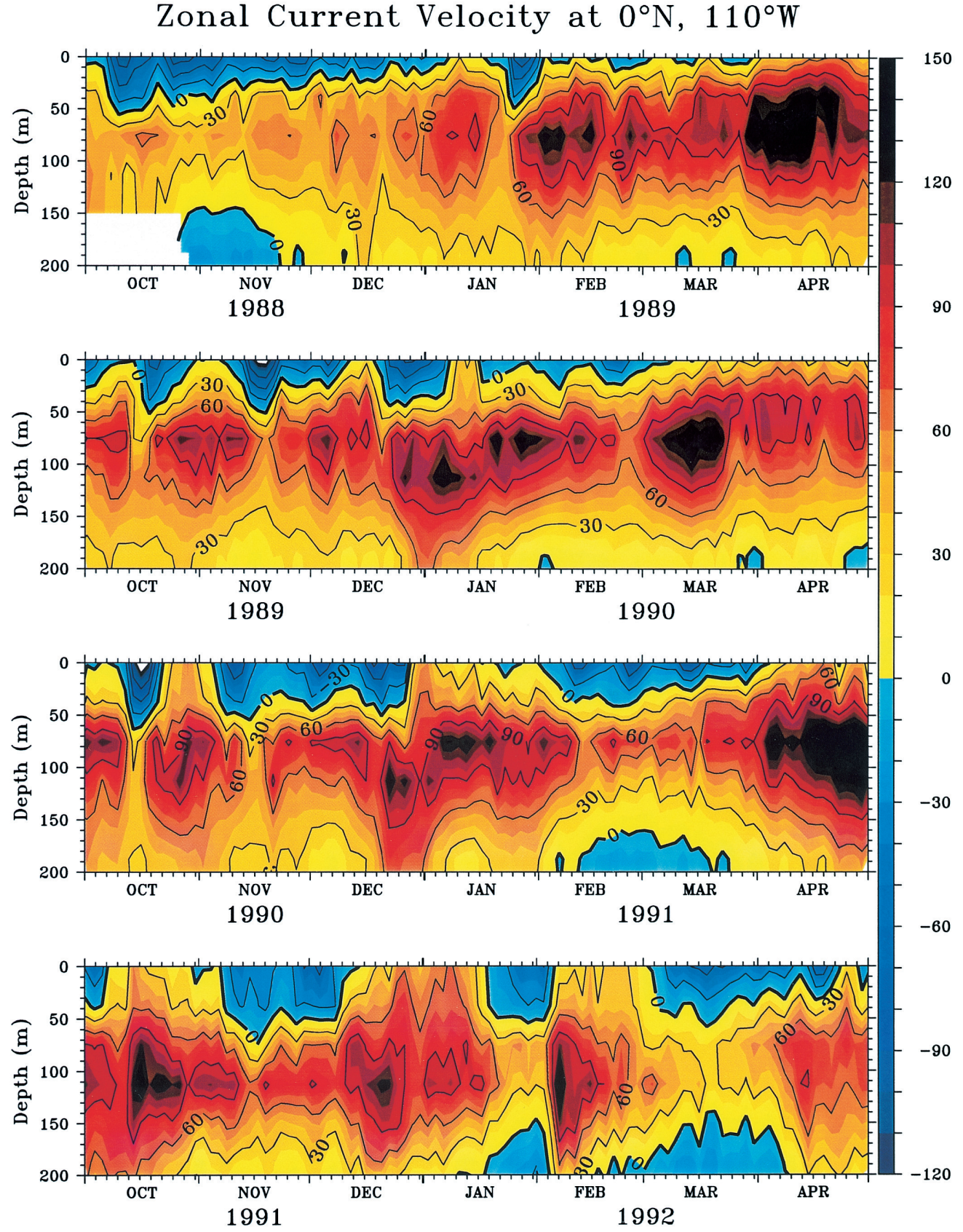

Fig. 6. Same as Fig. 3 except at $0^{\circ} \mathrm{N}, 110^{\circ} \mathrm{W}$. 


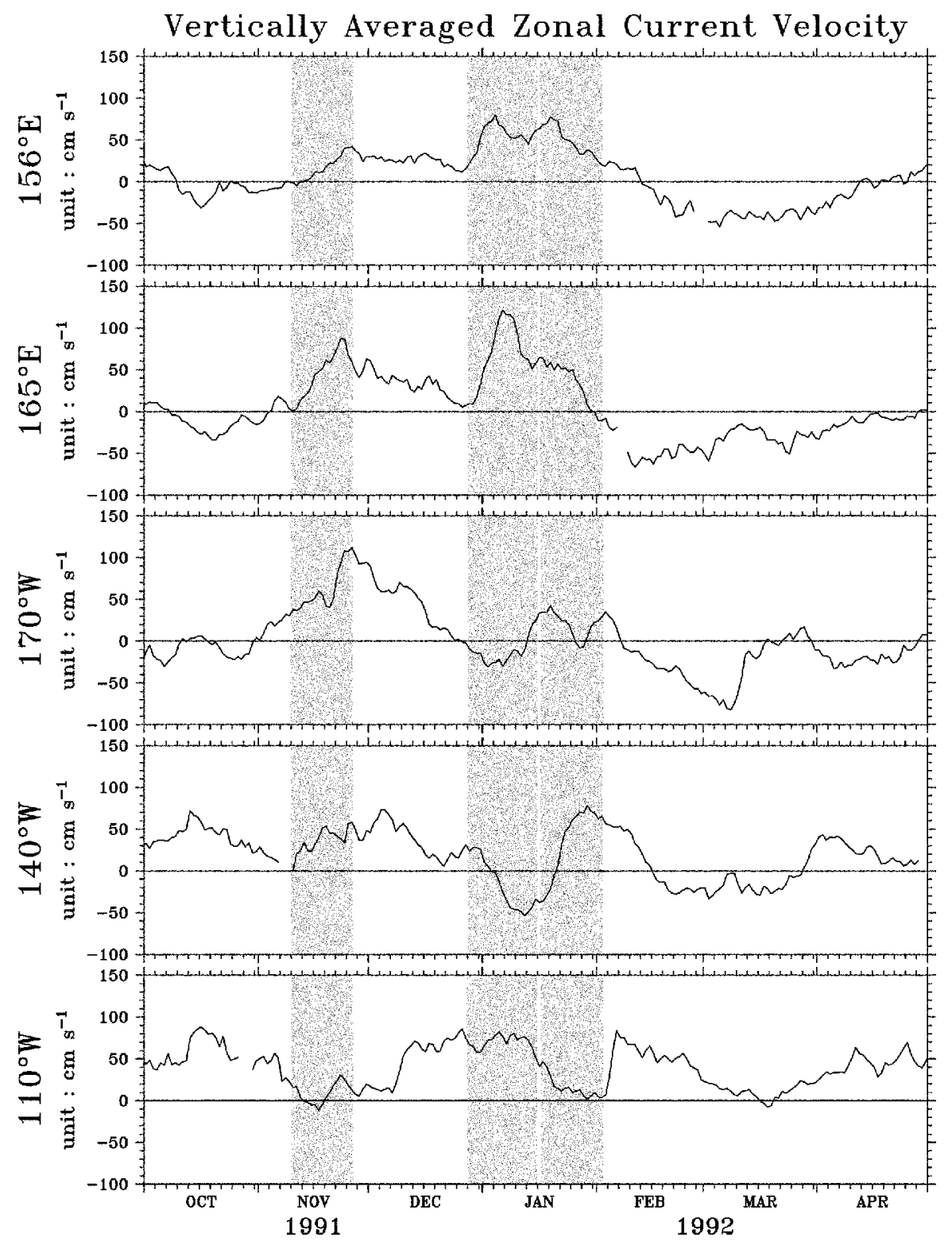

Fig. 7. Vertically-averaged upper ocean $(100 \mathrm{~m})$ zonal current velocity from October 1991 to April 1992 at $156^{\circ} \mathrm{E}, 165^{\circ} \mathrm{E}, 170^{\circ} \mathrm{W}, 140^{\circ} \mathrm{W}$ and $110^{\circ} \mathrm{W}$ on the equator. The three shaded regions indicate the intervals of the three major WWB events. Vertically-averaged zonal current velocity is measured in $\mathrm{cm} \mathrm{s}^{-1}$. 


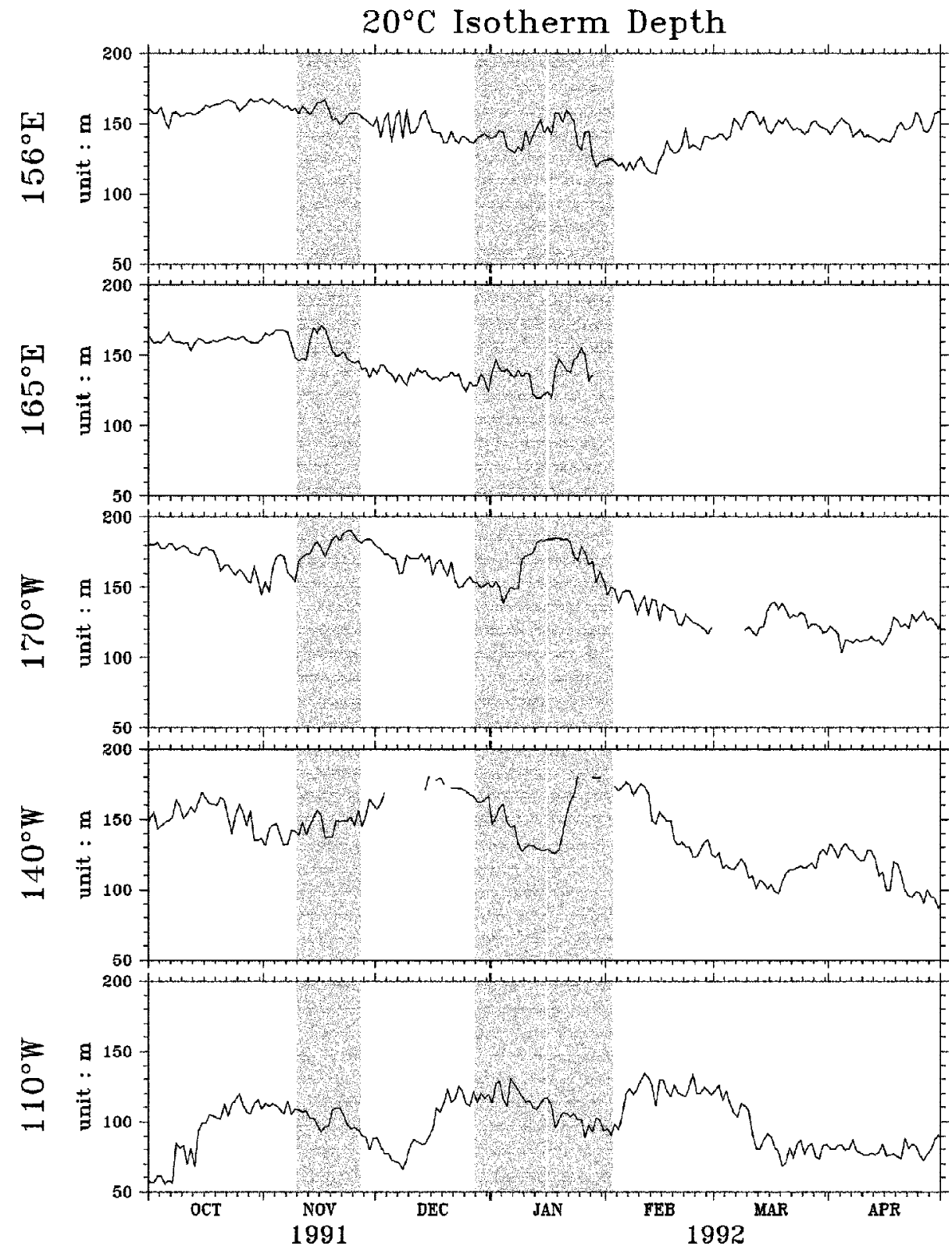

Fig. 8. $20^{\circ} \mathrm{C}$ isotherm depth from October 1991 to April 1992 at $156^{\circ} \mathrm{E}, 165^{\circ} \mathrm{E}$, $170^{\circ} \mathrm{W}, 140^{\circ} \mathrm{W}$ and $110^{\circ} \mathrm{W}$ on the equator. The three shaded regions indicate the intervals of the three major WWB events. $20^{\circ} \mathrm{C}$ isotherm depth is measured in $\mathrm{m}$. The data are provided by the TAO Project Office, Pacific Marine Environmental Laboratory, National Oceanic and Atmospheric Administration, USA. 


\section{ANALYSIS}

The analytical ocean model used here is that of Weisberg and Tang (1990) and Yang et al. (1997) building upon the formalism of Cane and Sarachik (1976). It is a single active layer, linear, reduced gravity, $\beta$ - plane ocean model governed by the following equations:

$$
\begin{aligned}
& \frac{\partial u}{\partial t}-y v+\frac{\partial h}{\partial x}=\tau^{x}-\varepsilon u, \\
& \frac{\partial v}{\partial t}+y u+\frac{\partial h}{\partial y}=-\varepsilon v, \\
& \frac{\partial h}{\partial t}+\frac{\partial u}{\partial x}+\frac{\partial v}{\partial y}=-\varepsilon h,
\end{aligned}
$$

where $u$ and $v$ are current velocity components in $x$ (zonal) and $y$ (meridional), $h$ is upper layer thickness perturbation, $t$ is time, $\tau^{x}$ is zonal wind stress, and $\varepsilon$ is a damping parameter. The equations are non-dimensionalized along time and length scales $T=(\mathrm{c} \beta)^{-1 / 2}$ and $L=(\mathrm{c} / \beta)^{1 / 2}$, where $c=\left(g^{\prime} D\right)^{1 / 2}$ is reduced-gravity wave speed, $g^{\prime}$ is reduced-gravity, $D$ is undistributed layer water depth, and $\beta$ is planetary vorticity gradient. The model is forced from a state of rest by temporally and spatially varying zonal wind stress distributions. Oceanic response is obtained by the Fourier transformation of the motion equations, the projection of the forcing function onto appropriate equatorial wave modes of the homogeneous equations, and the temporal integration and inversion of the Fourier transformation via long-wave approximation. Scales for time and distance were selected at 1.54 days and $333.33 \mathrm{~km}$, respectively, and obtained by assuming that $c=250 \mathrm{~cm} \mathrm{~s}^{-1}$. This figure closely approximates the results of Jonhson and McPhaden (1993), Kessler and McCreary (1993), and Kessler et al. (1995), and was applied in an analytical model for the Pacific Ocean by Tang and Weisberg (1984). The damping coefficient is 0.01 (equivalent to an $e$-folding time of 154 days).

Forcing induced by zonal wind stress is represented by a series of linear functions in time and space, formulated as:

$$
\begin{aligned}
& \tau^{x}=\gamma e^{-\frac{y^{2}}{2}} X(x) F(t) \\
& X(x)=\frac{x}{L_{1}} H(x)-\left(\frac{x}{L_{1}}+\frac{x-L_{1}-L_{2}}{L_{2}}\right) H\left(x-L_{1}\right)+\frac{x-L_{1}-L_{2}}{L_{2}} H\left(x-L_{1}-L_{2}\right), \\
& F(t)=\frac{t}{T_{1}} H(t)-\left(\frac{t}{T_{1}}+\frac{t-T_{1}-T_{2}}{T_{2}}\right) H\left(t-T_{1}\right)+\frac{t-T_{1}-T_{2}}{T_{2}} H\left(t-T_{1}-T_{2}\right),
\end{aligned}
$$


where $H$ is the Heaviside step function, $L_{1}$ and $L_{2}$ specify zonal length of wind patch, $T_{1}$ and $T_{2}$ specify time variations, and $\gamma$ is wind stress magnitude. The meridional distribution of each zonal wind stress patch is assumed to be Gaussian and centered on the equator.

A schematic of the model forcing functions offering approximate representations of the three major WWB events from October 1991 to April 1992 is shown in Fig. 9. Labeled WI, WII, and WIII, each individual event is comprised of several stationary wind patches. Easterly winds during WWB events remained relatively steady with some notable exceptions, as in the central basin in late November. Since equatorial waves can also be generated by easterly wind stress fluctuations, a central basin easterly wind patch (labeled E) was also considered.

For each wind patch, each variation could generate two forced waves, first meridional Rossby and Kelvin waves, which generated directly by the external zonal wind, and a series waves reflected from two meridional boundaries. All of these waves constructed the model responses of $u$ and $h$. More detail discussion can be found in Cane and Sarachik $(1976,1977)$, Weisberg and Tang $(1983,1985,1987,1990)$, Tang and Weisberg (1984), and Yang et al. (1997). Modeled $u$ at $156^{\circ} \mathrm{E}, 165^{\circ} \mathrm{E}, 170^{\circ} \mathrm{W}, 140^{\circ} \mathrm{W}$ and $110^{\circ} \mathrm{W}$ to the three westerly wind events, individually and collectively, are shown in Fig. 10. Generally speaking, the time evo-

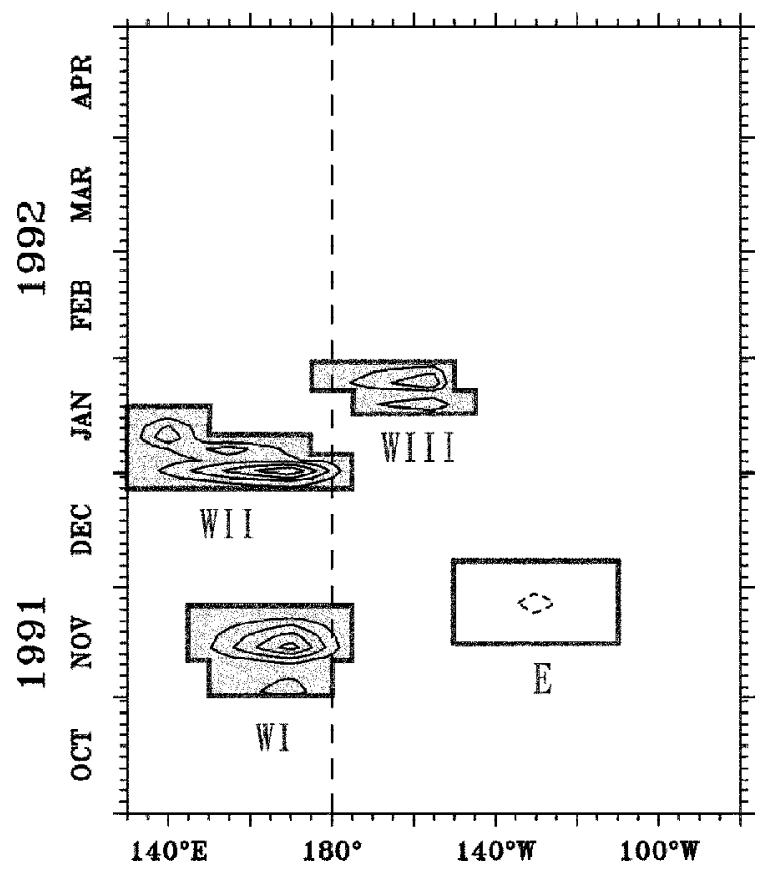

Fig. 9. Modeling force distribution as a function of time and longitude from October 1991 to April 1992 and $130^{\circ} \mathrm{E}$ to $80^{\circ} \mathrm{W}$. The contour interval is 0.3 dyne $\mathrm{cm}^{-2}$. The three major WWB events are indicated by the three wind patches labeled WI, WII and WIII. E represents easterly winds fluctuations. 


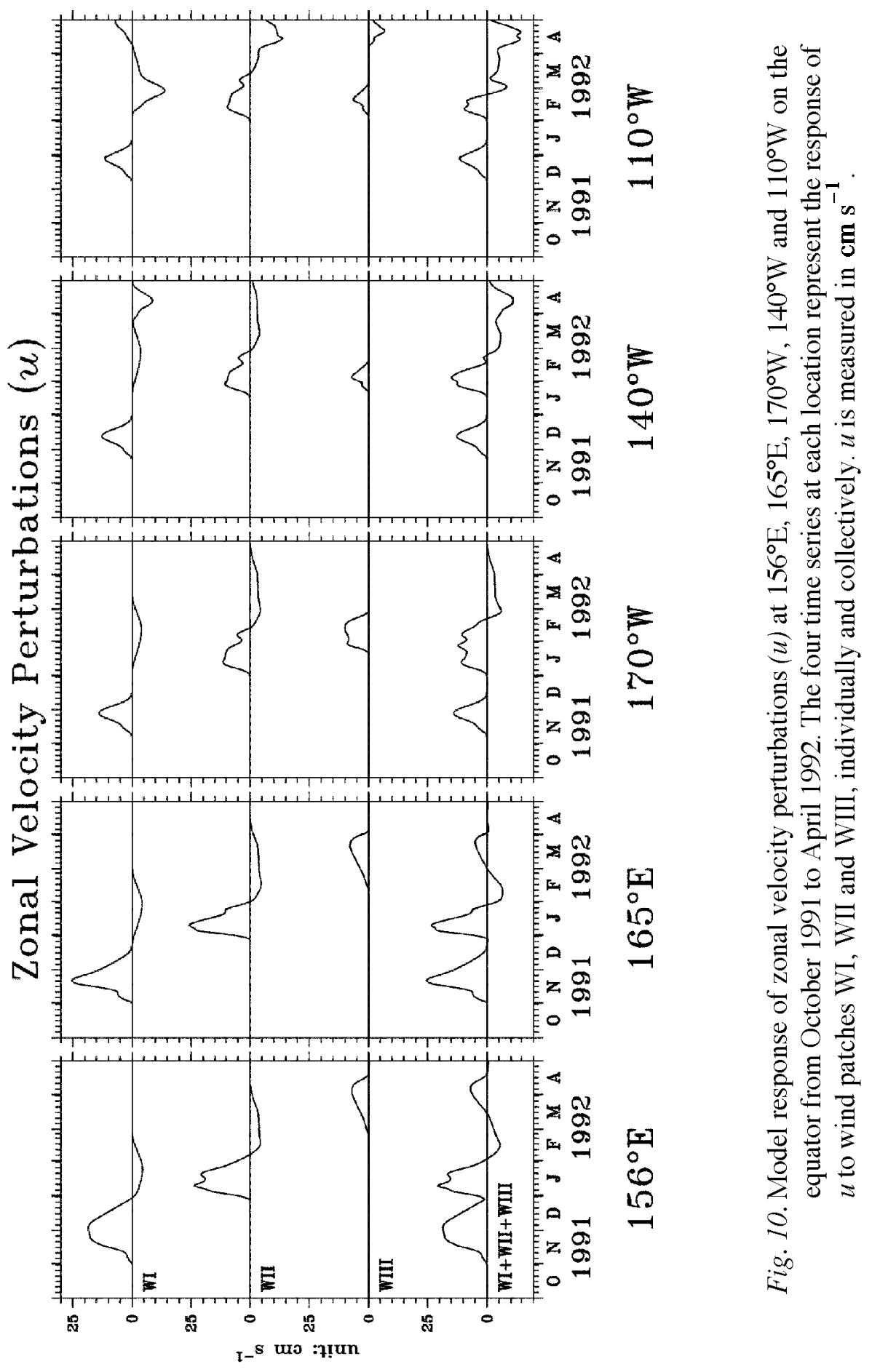


lution for $u$ within the west-central, central, and eastern basins during the first two WWB events are approximately the same. The time evolution of $u$ at $156^{\circ} \mathrm{E}$ and $165^{\circ} \mathrm{E}$ in the western basin is different, since these two locations are in the forced region where the local acceleration that forms the Yoshida jet (Yoshida 1959; O'Brien and Hurlburt 1974) is dependent upon local wind stress and limited by a local horizontal pressure gradient gradually established as the tails of forced Kelvin or Rossby waves from the ends of the wind patch pass an observed location (Weisberg and Tang 1987). Its location within the wind patch is therefore essential in determining the time evolution of $u$. The eastward velocity perturbation, for example, contains longer duration and smaller amplitude at $156^{\circ} \mathrm{E}$ than at $165^{\circ} \mathrm{E}$ during the first event. This smaller amplitude is related to the relative weakness of local zonal wind stress, while the longer duration can be attributed to the fact that the forced Rossby wave takes a longer time to pass this point. The wind patch of the third event occurs primarily east of the dateline. The first meridional mode Rossby and Kelvin waves propagate to the west and east, respectively (Weisberg and Tang 1983), beginning from the west-central basin in the forced region. The largest peak of $u$ for this event is therefore located at $170^{\circ} \mathrm{W}$. Though ocean response is induced primarily by forced waves, it can also be affected by reflected waves, especially for locations in close proximity to the boundaries (Weisberg and Tang 1985).

Though the propagation of peaks for $u$ can be traced easily in individual events, it becomes less clear with the collective consideration of three separate events. Values for $u$ generated by the second and third events, for example, cannot be clearly separated east of $170^{\circ} \mathrm{W}$. Its small size and the presence of a reflected Kelvin wave from the second event render the $u$ generated by the third event in the western basin almost undetectable. Moreover, the time of maximum eastward velocity of the second event at $156^{\circ} \mathrm{E}$ and $165^{\circ} \mathrm{E}$ is slightly shifted by a reflected Kelvin wave from the first event. Evolution of each peak can therefore be attributed to the interference pattern of the various waves formed by various wind fluctuations. Though model responses for $u$ generally correspond well with empirical observations, important differences still exist, particularly within the central and western basins. Observations at $170^{\circ} \mathrm{W}$, for example, indicate an eastward velocity with a significantly smaller amplitude in the second peak as compared to the first, while model results show similar amplitudes. This discrepancy will be resolved later.

Similar representations of model responses of $h$ at $156^{\circ} \mathrm{E}, 165^{\circ} \mathrm{E}, 170^{\circ} \mathrm{W}, 140^{\circ} \mathrm{W}$, and $110^{\circ} \mathrm{W}$ to the three WWB events, individually and collectively, can be found in Fig. 11. Increasing (decreasing) values for $h$ indicate downwelling (upwelling). The evolution of $h$ in the forced region is rather complex. Downwelling and upwelling appear alternately, contingent upon the passage of Kelvin and Rossby waves from the extremes of the wind patch (Weisberg and Tang 1985, 1987). Since the Rossby and Kelvin waves are out-of-phase with respect to $h$, $h$ has a much smaller amplitude within than without the forced region, and its fluctuations are opposite on either side of the forced region. It is important to note that these two features are opposed to the behavior of $u$, which is largest in the forced region and of the same sign on both sides of the forced region. The large amplitude of $h$ east of the forced region makes it a more useful tool than $u$ for tracing wave propagation east of the forced region, but without clear amplitude distinction, tracing wave propagation across the entire basin is still difficult. As with $u$, the $h$ induced by the second and third WWB events east of $170^{\circ} \mathrm{W}$ is non-separable. 


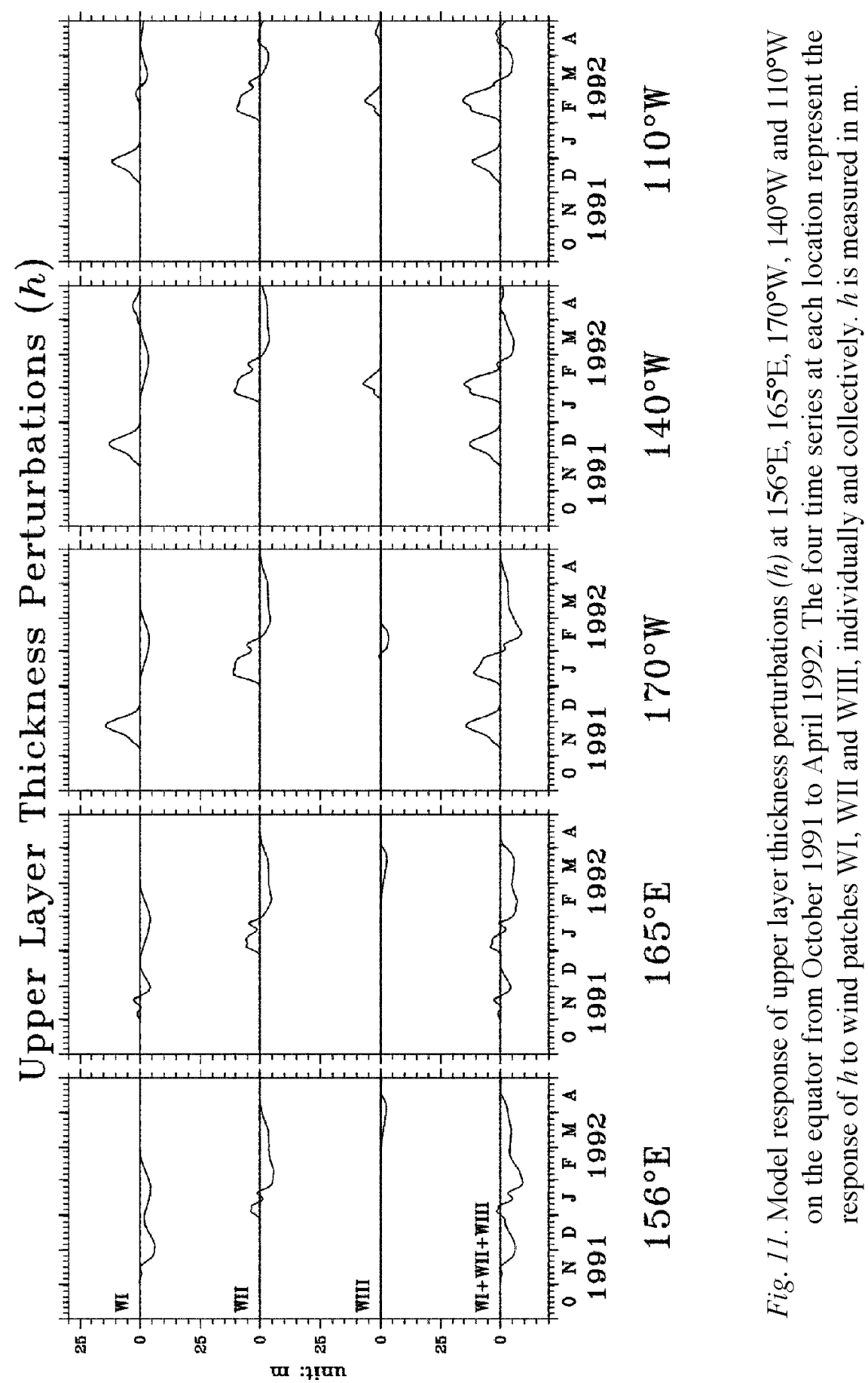


The correspondence for $h$ between modeled ocean responses and empirical observations in the central and eastern basins is therefore closer than for $u$, though the opposite proves true in the western basin.

Ocean responses to WWB events are also affected by ocean responses to easterly wind fluctuations east of the dateline. Figure 12 indicates ocean response to the easterly wind patch shown in Fig. 9. The largest amplitude of $u$ and the smallest amplitude of $h$ for the easterly wind patch occur in the forced region at $140^{\circ} \mathrm{W}$, while an upwelling Kelvin and downwelling first meridional mode Rossby wave are seen east and west of the wind patch, respectively (Weisberg and Tang 1985, 1987). Depending on the timing of wave arrival, the impact of the easterly wind patch on ocean response varies with location, modulating the third peak of $u$ in the western basin, the second peak of $u$ in the west-central basin, and the first peak in the central and eastern basins. Unlike $u$, the influence on $h$ is generally negligible except in the eastern basin. Therefore, peaks induced mainly by WWBs are further modulated by easterly wind fluctuations east of the dateline. The complexity of such interference patterns contributes to the spatial and temporal variation of peak formation in both $u$ and $h$, making the tracing of wave propagation via peak-to-peak comparison somewhat misleading. With the speed of a Kelvin wave, an eastwardly propagation peak, generated by a WWB, could be modified by a westward propagating Rossby wave, generated by another easterly wind patch east of the WWB. Furthermore, Weisberg and Tang (1990) pointed out that the coherence of ocean responses to the wind forcing varies from location to location primarily due to differences in the arrival time of various forced and reflected waves at different locations.

The comparisons between $u$ and vertically averaged upper ocean zonal velocity and between $h$ and $20^{\circ} \mathrm{C}$ isotherm depth can be found in Figs. 13, 14, respectively. Their correlation coefficients are shown in Table 1. Both empirical data and model results have been de-averaged, normalized, and plotted together. The correlation coefficients have little change with the vertically averaged upper ocean current velocity obtained from the integration over various depths. This result indicates that the SEC and EUC has nearly in-phase variation in the time scale of a WWB. In general, $u$ correlates well with vertically averaged upper ocean zonal velocity in the west-central and western basins, while $h$ correlates well with $20^{\circ} \mathrm{C}$ isotherm depth in the central and eastern basins. Despite the small amplitude of $h$ within the forced region, its correspondence with $20^{\circ} \mathrm{C}$ isotherm depths west of the dateline is poor. Such results are owing to that the $u$ has more direct and larger response in the forced region than outside (Yoshida 1959; O'Brien and Hurlburt 1974). Conversely, the $h$ has smaller amplitude in a forced region than outside (Weisberg and Tang 1985). Of course the correspondence of both $u$ and $h$ is generally poor after March 1992, when easterly winds collapsed across the entire basin (the schematic model of Fig. 9 ends in February).

\section{DISCUSSIONS AND SUMMARY}

The reversal of the SEC response to the WWB in the western basin differs from that caused by the surfacing of the EUC often observed in the central and eastern basins. The former is generally accompanied by the reversal of its vertical gradient in the upper ocean 

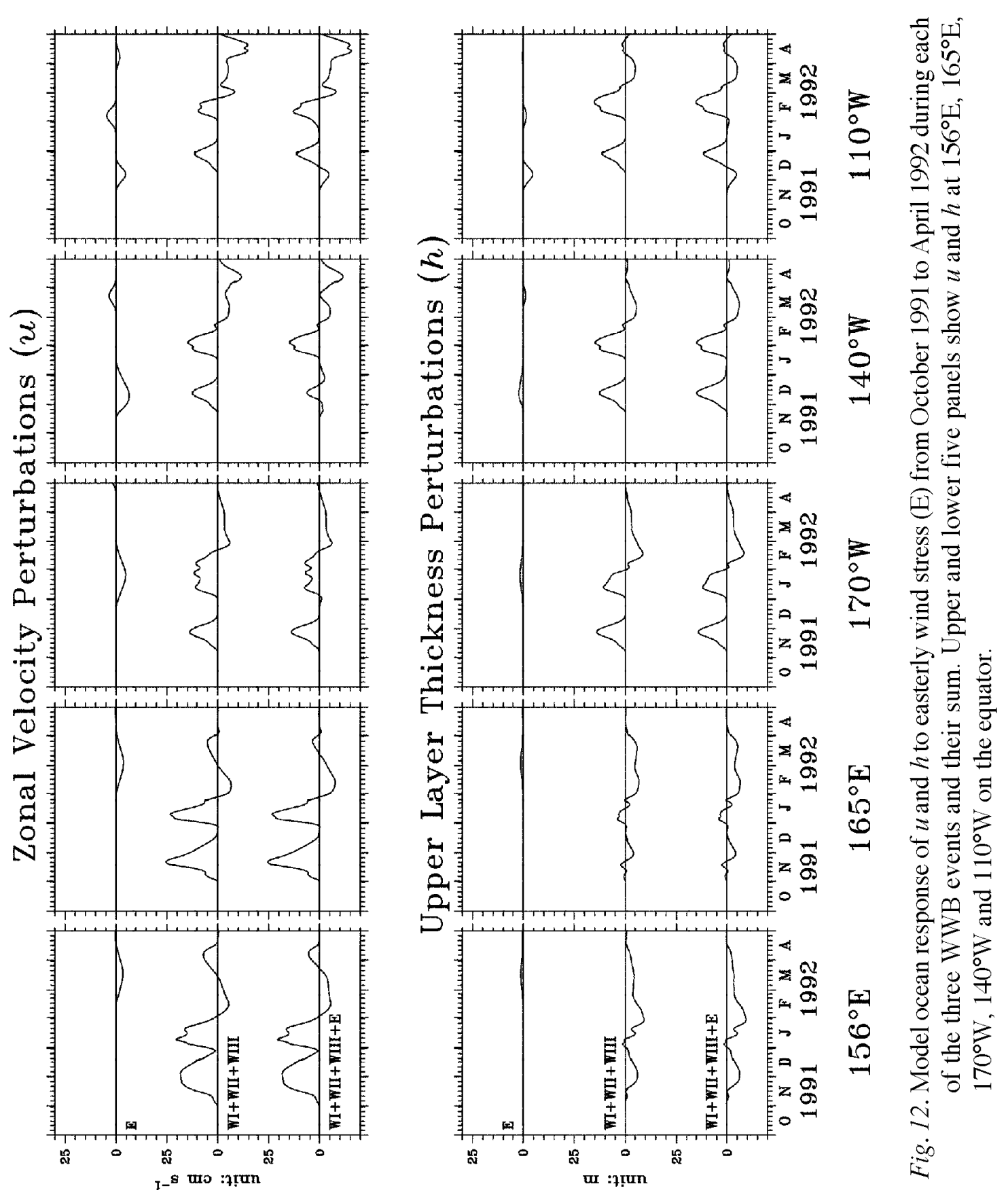


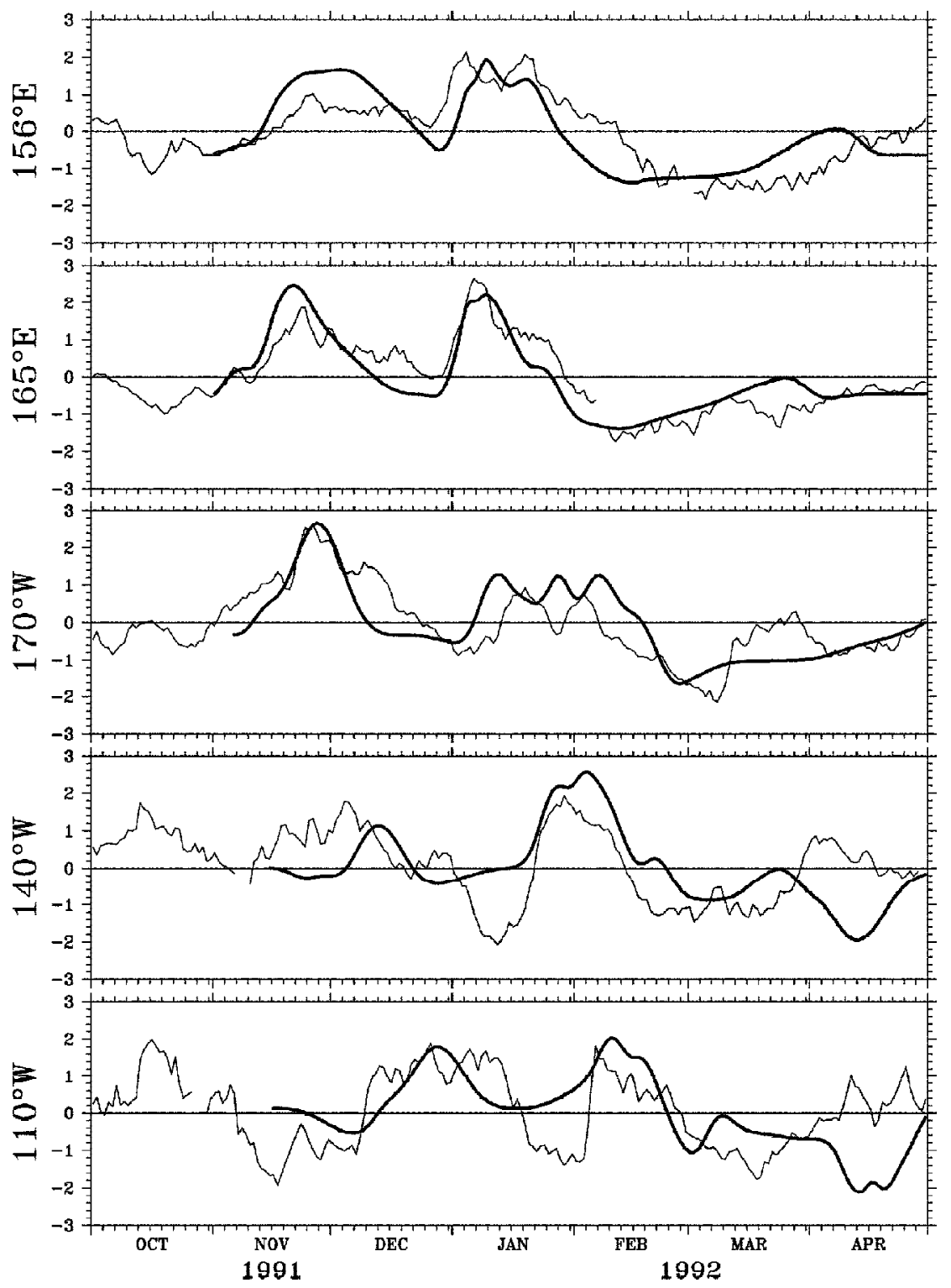

Fig. 13. Comparison between $u$ and vertically-averaged upper ocean zonal current velocity at $156^{\circ} \mathrm{E}, 165^{\circ} \mathrm{E}, 170^{\circ} \mathrm{W}, 140^{\circ} \mathrm{W}$ and $110^{\circ} \mathrm{W}$ on the equator from October 1991 to April 1992. Both time series are de-averaged, normalized, and overlapped. Thin and bold lines indicate vertically-averaged upper ocean zonal current velocity and $u$, respectively. 


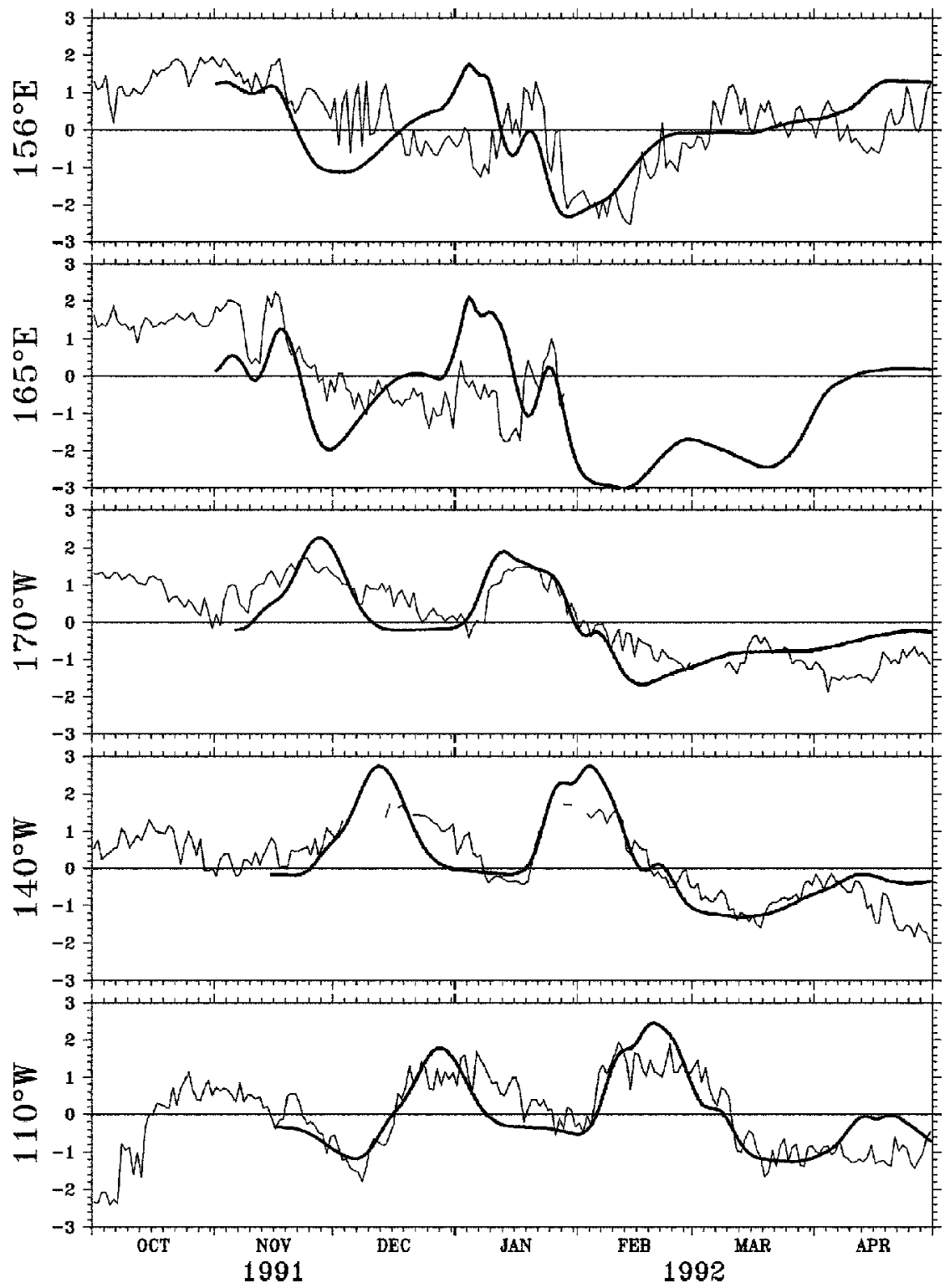

Fig. 14. Comparison between $h$ and $20^{\circ} \mathrm{C}$ isotherm depth at $156^{\circ} \mathrm{E}, 165^{\circ} \mathrm{E}, 170^{\circ} \mathrm{W}$, $140^{\circ} \mathrm{W}$ and $110^{\circ} \mathrm{W}$ on the equator from October 1991 to April 1992. Both time series are de-averaged, normalized, and overlapped. Thin and bold lines indicate $20^{\circ} \mathrm{C}$ isotherm depth and $h$, respectively. 
Table 1. The correlation coefficients between $u$ and vertically-averaged upper ocean zonal current velocity and between $h$ and $20^{\circ} \mathrm{C}$ isotherm depth at $156^{\circ} \mathrm{E}, 165^{\circ} \mathrm{E}, 170^{\circ} \mathrm{W}, 140^{\circ} \mathrm{W}$ and $110^{\circ} \mathrm{W}$ on the equator from October 1991 to April 1992.

\begin{tabular}{|c|c|c|}
\hline Location & $\begin{array}{c}\text { Correlation Coefficient between } u \\
\text { and vertically-averaged upper ocean } \\
\text { zonal current velocity }\end{array}$ & $\begin{array}{c}\text { Correlation Coefficient between } h \\
\text { and } 20^{\circ} \mathrm{C} \text { isotherm depth }\end{array}$ \\
\hline $156^{\circ} \mathrm{E}$ & 0.73 & 0.47 \\
\hline $165^{\circ} \mathrm{E}$ & 0.86 & 0.17 \\
\hline $170^{\circ} \mathrm{W}$ & 0.73 & 0.81 \\
\hline $140^{\circ} \mathrm{W}$ & 0.40 & 0.81 \\
\hline $110^{\circ} \mathrm{W}$ & 0.38 & 0.79 \\
\hline
\end{tabular}

from negative to positive. Using an equatorial mixed layer model, McPhaden et al. 1988 inferred a relation between the reversal of the vertical gradient of zonal velocity and large vertical eddy viscosity, but this is not the case in the west-central basin. During the second event (January 1992), surface zonal current and its vertical gradient were reversed at $170^{\circ} \mathrm{W}$ (Fig. 4) and local wind was generally weak (Fig. 1), undermining the importance of the mixing effect. With its eastward velocity and positive vertical gradient of zonal velocity, the baroclinic mode of the Kelvin wave could be responsible for these reversals. The initially negative local gradient of zonal velocity also seems to be important for the determination of vertical gradient reversal. If the local vertical gradient of zonal velocity were strong, it could not be reversed by a large WWB, which only induces surfacing of the EUC or reduction of the SEC. The large WWB observed in late November 1989 (Fig. 1), for example, only induced the surfacing of the EUC in December (Fig. 4); the vertical gradient of zonal velocity remained negative.

Equatorial zonal wind stress, upper ocean zonal current velocity, and $20^{\circ} \mathrm{C}$ isotherm depth in the Pacific Ocean were examined for the period of WWBs generally occurring between October and April from 1988 (La Niña year) to 1991 (El Niño year). Zonal wind stress was calculated from the ECMWF model output; zonal current velocity and $20^{\circ} \mathrm{C}$ isotherm depth measurements were taken from moorings at $156^{\circ} \mathrm{E}, 165^{\circ} \mathrm{E}, 170^{\circ} \mathrm{W}, 140^{\circ} \mathrm{W}$ and $110^{\circ} \mathrm{W}$ along the equator. The observed increase in WWB frequency and strength as well as the eastward shift of their fetch in the period between La Niña and El Niño is consistent with previous findings (Kindle and Phoebus 1995). Westward surface current and vertical gradient in the western basin both reversed in response to WWB events. The difference between the central and eastern basins and that in the west lies in the absence of vertical gradient reversal in the latter, where eastward surface current was contiguous with EUC movement. In the transitional region in the west-central basin between the warm pool to the west and cold tongue to the east, reversals of surface current and vertical gradient were only observed during the El Niño period. 
Fluctuations in upper ocean zonal current were largest in the west-central basin, while fluctuations in $20^{\circ} \mathrm{C}$ isotherm depths due to WWBs were largest in the central and eastern basins. On a basin-wide scale, the modulation of ocean responses (including both thermal and zonal current variations) to WWB events occurred during their propagation away from the forced region.

A simple analytical ocean model was used to describe the spatial and temporal evolution of ocean responses to the major WWB events during the 1991-1992 El Niño. Attributable to the temporal proximity of individual WWB events, the interference of these ocean responses varies with location and time. The additional interference of easterly wind fluctuations east of the dateline makes the pattern evolution for both upper ocean current and thermal structure an extremely complex function of time and space. Observed peaks in ocean responses at different locations or times may therefore be associated with complex interference patterns, rendering individual wave mode tracing via peak-to-peak comparison an extremely subjective process.

The strengthening of the negative vertical gradient of zonal velocity in the upper ocean seems to be an important determinant of its reversal in response to WWB events. Generally weak in the western basin and strong in the eastern basin, the negative vertical gradient of zonal velocity frequently reverses in the former and remains the same in the latter. Vertical gradient reversal of zonal current in the west-central basin could only be found in the initial stages of El Niño as a result of its gradual weakening in the period between La Niña and El Niño.

Acknowledgments This work was supported by the National Science Council, R.O.C., under the grant NSC 85-2611-M-002A-006-AGT and by the National Science Foundation under the grant OCE-9525912. We would like to thank the TAO Project Office for providing current and temperature data. The assistance of Mr. Jeff Donovan and Rick Cole during the deployment and recovery of ADCP currentmeter moorings is also greatly appreciated.

\section{REFERENCES}

Cane, M., and E. S. Sarachik, 1976: Forced baroclinic ocean motions, I: The linear equatorial unbounded case. J. Mar. Res., 34, 629-665.

Cane, M., and E. S. Sarachik, 1977: Forced baroclinic ocean motions, II: The linear equatorial bounded case. J. Mar. Res., 35, 395-432.

Firing, E., R. Lukas, J. Sadler, and K. Wyrtki, 1983: Equatorial Undercurrent disappears during 1982-1983 El Niño. Science, 222, 1121-1123.

Giese, B. S., and D. E. Harrison, 1991: Eastern equatorial Pacific response to three composite westerly wind types. J. Geophys. Res., 96, 3239-3248.

Harrison, D. E., and B. S. Giese, 1991: Episodes of surface westerly wind as observed from islands in the western tropical Pacific.J. Geophys. Res., 96, 3221-3237.

Hayes, S. P., L. J. Mangum, J. Picaut, A. Sumi, and K. Takeuchi, 1991: TOGA-TAO: A moored array for real-time measurements in the tropical Pacific Ocean.Bull. Am. Metor. Soc., 72, 339-347. 
Hisard, P., J. Merel, and B. Voituriez, 1970: The Equatorial Undercurrent at 170 E in March and April 1967. J. Mar. Res., 28, 281-303.

Jonhson, E. S., and M. J. McPhaden, 1993: Structure of intraseasonal Kelvin waves in the equatorial Pacific Ocean. J. Phys. Oceanogr., 23, 608-625.

Keen, R. A., 1982: The role of cross-equatorial tropical cyclone pairs in the Southern Oscillation. Mon. Weather Rev., 110, 1405-1416.

Keen, R. A., 1988: Equatorial westerlies and Southern Oscillation. p. 121-140. In: Lukas R., and P. Webster, (Eds.), Proceedings of U.S. TOGA Western Pacific Air-Sea Interaction Workshop, Tech. Rep. USTOGA-8, Univ. Corp. for Atmos. Res., Boulder, Colo., USA, 121-140.

Kessler, W. S., and J. P. McCreary, 1993: The annual wind-driven Rossby wave in the subthermocline equatorial Pacific. J. Phys. Oceanogr., 23, 1192-1207.

Kessler, W. S., and M. J. McPhaden, 1995a: The 1991-1993 El Niño in the central Pacific. Deep-Sea Res., 42, 295-333.

Kessler, W. S., and M. J. McPhaden, 1995b: Oceanic equatorial waves and the 1991-93 El Niño. J. Clim., 8, 1757-1774.

Kessler, W. S., B. A. Taft, and M. J. McPhaden, 1985: Assessment of the XBT sampling network in the central tropical Pacific. Univ. Crop. Atmos. Res., US TOGA 4, 62pp.

Kessler, W. S., M. J. McPhaden, and K. M. Weickmann, 1995: Forcing of intraseasonal Kelvin Waves in the equatorial Pacific. J. Geophys. Res., 100, 10613-10631.

Kessler, W. S., M. C. Spillane, M. J. McPhaden, and D. E. Harrison, 1996: Scales of variability in the equaorial Pacific inferred from the Tropical Atmosphere-Ocean buoy array. J. Clim., 9, 2999-3024.

Kindle, J. C., and P. A. Phoebus, 1995: The ocean response to operational westerly wind bursts during the 1991-1992 El Niño. J. Geophys. Res., 100, 4893-4920.

Luther, D. S., D. E. Harrison, and R. A. Knox, 1983: Zonal winds in the central equatorial Pacific and El Niño. Science, 222, 327-330.

McPhaden, M. J., 1993: TOGA-TAO and the 1991-93 El Niño-Southern Oscillation event. Oceanogr., 6, 36-44.

McPhaden, M. J., and S. P. Hayes, 1991: On the variability of wind, sea surface temperature and surface layer heat content in the western equatorial Pacific.J. Geophys. Res., 96, 3331-3342.

McPhaden, M. J., H. P. Freitag, S. P. Hayes, B. A. Taft, Z. Chen, and K. Wyrtki, 1988: The response of the equatorial Pacific Ocean to a westerly wind burst in May 1986. J. Geophys. Res., 93, 10589-10603.

McPhaden, M. J., F. Bahr, Y. du Penhoat, E. Firing. S. P. Hayes, P. P. Niller, P. L. Richardson, and J. M. Toole, 1992: The response of the western equatorial Pacific Ocean to westerly wind burst during November 1989 to January 1990.J. Geophys. Res., 97, 1428914303.

O'Brien, J. J., and H. E. Hurlburt, 1974: Equatorial jet in the Indian Ocean: Theory. Science, 184, 1075-1077.

Qiao, L., and R. H. Weisberg, 1997: The zonal momentum balance of the Equatorial Undercurrent in the central Pacific. J. Phys. Oceanogr., 27, 1094-1119. 
Rasmusson, E. M., P. A. Arkin, A. F. Krueger, R. S. Quiroy, and R. W. Reynolds, 1983: The equatorial Pacific atmospheric climate during 1982-83. Tropical Ocean-Atmosphere Newsletter, 21, 2-3.

Smyth, W. D., D. Hebert, and J. N. Moum, 1996a: Local ocean response to a multiphase westerly wind burst, 1: Dynamic response. J. Geophys. Res., 101, 22495-22512.

Smyth, W. D., D. Hebert, and J. N. Moum, 1996b: Local ocean response to a multiphase westerly wind burst, 2: Thermal and freshwater responses.J. Geophys. Res., 101, 2251322533.

Sprintall, J., and M. J. McPhaden, 1994: Surface layer variations observed in multiyear time series measurements from the western equatorial Pacific. J. Geophys. Res., 99, 963979.

Tang, T. Y., and R. H. Weisberg, 1984: On the equatorial Pacific response to the 1982/1983 El Niño-Southern Oscillation event. J. Mar. Res., 42, 809-829.

Trenberth, K. E., J. G. Olson, and W. G. large, 1989: A global ocean wind stress climatology based on ECMWF analyses. NCAR Tech. Note NCAR/TN-338+STR, Natl. Cent. for Atmos. Res., Boulder, Colo., USA, 93pp.

Weisberg, R. H., and S. P. Hayes, 1995: Upper ocean variability on the equator in the Pacific at $170^{\circ}$ W. J. Geophys. Res., 100, 20,485-20,498.

Weisberg, R. H., and T. Y. Tang, 1983: Equatorial ocean response to growing and moving wind systems with application to the Atlantic. J. Mar. Res., 41, 461-486.

Weisberg, R. H., and T. Y. Tang, 1985: On the response of the equatorial thermocline in the Atlantic Ocean to the seasonally varying Trade Winds. J. Geophys. Res., 90, 71177128.

Weisberg, R. H., and T. Y. Tang, 1987: Further studies on the response of the equatorial thermocline in the Atlantic Ocean to the seasonally varying Trade Winds.J. Geophys. Res., 92, 3709-3727.

Weisberg, R. H., and T. Y. Tang, 1990: A linear analysis of equatorial Atlantic Ocean thermocline variability. J. Phys. Oceanogr., 20, 1813-1825.

Wyrtki, K., 1975: El Niño-The dynamic response of the equatorial Pacific Ocean to atmospheric forcing. J. Phys. Oceanogr., 5, 572-584.

Wyrtki, K., and G. Meyers, 1976: The Trade Wind field over the Pacific Ocean. J. Appl. Meteor., 15, 698-704.

Yang, Y. J., T. Y. Tang, and R. H. Weisberg, 1997: Basin-wide zonal wind stress and ocean thermal variations in the equatorial Pacific Ocean.J. Geophys. Res., 102, 911-927.

Yoshida, K., 1959: A theory of Cromwell Current (the Equatorial Undercurrent) and of the equatorial upwelling-An interpretation in a similarity to the coastal circulation. $J$. Oceanogr. Soc. Japan, 15, 1-13. 